\title{
Histological Assessment of Nano Hydroxyapatite, Chitosan and Collagen Composite Coating on Commercially Pure Dental Implants in Comparison with Nanohyroxyapatite Coating
}

\author{
Sabreen W. Ibrahim ${ }^{1}$, Widad A. Al-Nakkash ${ }^{2}$, Nada M. Al Ghaban ${ }^{3}$ \\ ${ }^{1}$ Assistant Lecturer, Prosthodontic Department, College Of Dentistry, Al-MustansiriyahUniversity \\ ${ }^{2}$ Prof. Al- Esraa Private University Collage -Dentistry Department \\ ${ }^{3}$ Assistant Professor, Oral Histology\& Biology, College of Dentistry, Baghdad University
}

\begin{abstract}
After high success rate of using dental implants in restoration of missing teeth, attention now shifted toward immediate loading of dental implant through improving the osseointegration, this can achieved by coating the dental implants by biocompatible materials. The aim of this study was evaluation the osseointegration of dental implants histologically. Dip coating technique was used to obtain thin homogenous coating on commercially pure titanium screws. Tibia of 6 white New Zeeland rabbits was chosen as implantation site, screws divided into 2 groups, first group coated with nano hydroxyapatite, chitosan and collagen composite coating, second group coated with nano hydroxyapatite for 2 and 6 weeks of healing periods. Histological analysis showed increasing new bone formation for the nano hydroxyapatite, chitosan and collagen composite coated implants than nano hydroxyapatite coated implants and over the two periods of time. As conclusion screws coated with nano hydroxyapatite, chitosan and collagen composite was more efficient than nano hydroxyapatite coating
\end{abstract}

Keywords: osseointegration, Dip coating, hydroxyapatite, chitosan, collagen, composite

\section{Introduction}

Osseointegration can be defined as" the direct connection of osseous tissue to an inert, alloplastic material without intervening connective tissue" ${ }^{,(1,2)}$.

Success and failure of dental implants depend on osseointegration because it responsible for providing a stable bone-implant interface in order to support a dental prosthesis and transfer applied forces of occlusion without concentrating stresses at the implant-bone interface. Requirement for osseointegration is vital bone and space between the implant and host tissue must be less than $10 \mathrm{~nm}$ without formation of any fibrous tissue ${ }^{(3)}$.

Due to the biocompatibility and minimum foreign body reaction of titanium, titanium is widely used in fabrication of dental implants in comparison to other materials ${ }^{(4,5)}$. At the histological level, The implant surface quality ( include physicochemical composition and nano- and microtopography), have a direct effect on the osseointegration ${ }^{(6)}$.

$\mathrm{CaP}$ materials have the ability to bond directly to bone, while titanium doesn't has this ability, so, altering the surface characteristics of titanium have aimed to increase the bioactivity of titanium ${ }^{(7)}$. Calcium phosphate coatings enhance bone healing and deposition, resulting in rapid fixation of implants ${ }^{(8)}$.

Collagen and chitosan are polymer, the characteristic feature of polymer is the compatibility with human tissue ${ }^{(9)}$.
Collagen is the main component of human body, it responsible for tensile strength and flexibility of bone ${ }^{(10)}$.

Chitosan has been widely used in bone tissue engineering due to its biocompatibility and has the ability to enhance growth of osteoblasts in culture without inflammatory reactions or toxic degradation ${ }^{(11)}$. Aim of this study is histological evaluation of nano HA ,chitosan and collagen composite as a coating material

\section{Material and Methods}

\section{Materials}

- Commercially pure titanium rod (CpTi) rod grade (Orotig S rl EU company, Italy). - Hydroxyapatite powder (Particles size 98.5\%, <40nm), sky spring nanomaterial, USA.)

- Chitosan powder (degree of deacetylation 85\%) (Xian Lyphar Biotechnology Co. china).

- Collagen (C5608, Sigma Aldrich, USA)

- Ethanol absolute 99.8\%. (Sigma Aldrich, Germany).

- $\mathrm{P}_{2} \mathrm{O}_{5}$ (Emphos PS-21A, Witco).phosphorous pentoxide, (as thickening material)

- Argon gas(Iraq).

- Acetic acid 2\% (Scharlau S.L., Spain).

- Optical microscope (Olympus 1542037 , Japan).

- Prosthetic engine having straight hand piece (Marathon Saeyang Microtech, Korea)

- Canada balsam (Batch NO. 10862501, European Union).

- Ethanol alcohol $96 \%$.

- Formaldehyde 37\%.

- Formic acid 10\% (Batch NO. 28380, England). 


\section{International Journal of Science and Research (IJSR) \\ ISSN (Online): 2319-7064}

Index Copernicus Value (2015): 78.96 | Impact Factor (2015): 6.391

- Hematoxylen and eosin (H\&E) (Dako, U.S.A).

- Microscopic glass slides and covers (China).

- Paraffin wax (Hinweis, U.K.D).

\section{Methods}

After machining of Commercially pure titanium rod into 18 screw shape implants with $3.0 \mathrm{~mm}$ in diameter and $8 \mathrm{~mm}$ in length (threaded part is $5 \mathrm{~mm}$ and smooth part is $3 \mathrm{~mm}$ ) and pitch height is $1 \mathrm{~mm}$.

Cleaning and removing of the oxide layer from the surface of screw shape implants was done by using solution consists of $30 \%$ of HNO 3 and $10 \%$ of HF in distilled water then screws were washed by distilled water. After that screws were put in ethanol for 15 minute in ultrasonic cleaner bath, washed by distilled water and dried by oven $100^{\circ} \mathrm{c}$ for 15 minutes.

Screws divided into two groups, first group coated with nano hydroxyapatite by dip coating, while second group coated with nano hydroxyapatite-chitosan-collagen composite by dip coating. The nano hydroxyapatite suspension involve dissolution of $0.01 \mathrm{~g}$ of $\mathrm{P}_{2} \mathrm{O}_{5}$ in $50 \mathrm{ml}$ of absolute alcohol (ethanol) with continuous mixing, Then $(7 \mathrm{~g})$ of nanohydroxyapatite powder was added to the solution ${ }^{(12)}$, second solution prepared by dissolving of collagen in chitosan solution(chitosan solution prepared by dissolving $0.5 \mathrm{~g}$ of chitosan in $50 \mathrm{ml}$ of $2 \%$ acetic acid)then mixed with nano hydroxyapatite solution( $4 \mathrm{~g}$ of nanoHA in $50 \mathrm{ml}$ of ethanol). First group sintered at $400^{\circ} \mathrm{C}$.while second group coated sintered at $100^{\circ} \mathrm{C}$.

\section{Surgical Procedure}

Six healthy adult male New Zeeland rabbits, weighing 2 $2.5 \mathrm{~kg}$, about 11 months age were used. X- Ray was taken prior to surgery (figure 1) to ensure absence of inflammation and adequate bone present for placing the implants. Atraumatic surgery was performed to place the implants in holes in the rabbit tibia, nanohydroxyapatite coated implants placedin hole in right tibia while nano hydroxyapatite ,chitosan and collagen composite coated dental implant placed in hole in left tibia,scarification of the animals was done after $2 \& 6$ weeks.

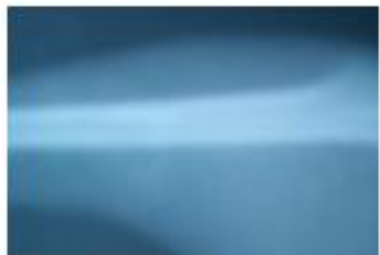

Figure 1: X-ray radiograph prior surgery

\section{Results}

At the day of sacrifice all implants could not be moved with manual forceand were found to stable in its place in the bone, without gross inflammation in the bone, Implants were surrounded by well-developed bone tissue for both coated implant after two and six weeks of healing intervals as illustrated in as shown in (figure $2 \& 3$ ).
Radiographic evaluation have shown that therewere no areas of radiolucency between theimplant and adjacent cortical bone (figure4).

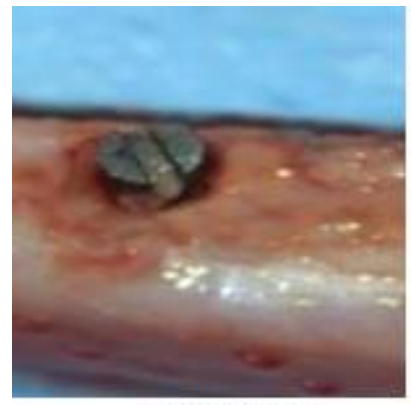

(A)Right tibia

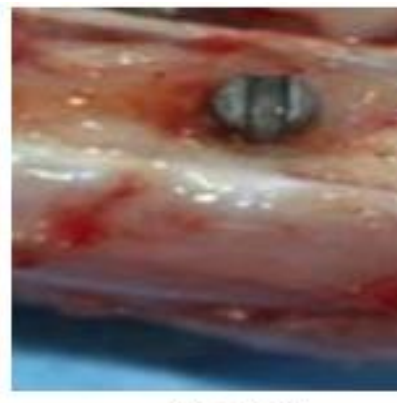

(B) left tibia
Figure 2: Surgical site after 2 weeks

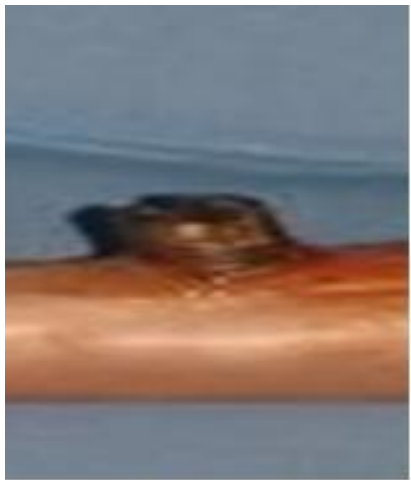

(A) Right tibia

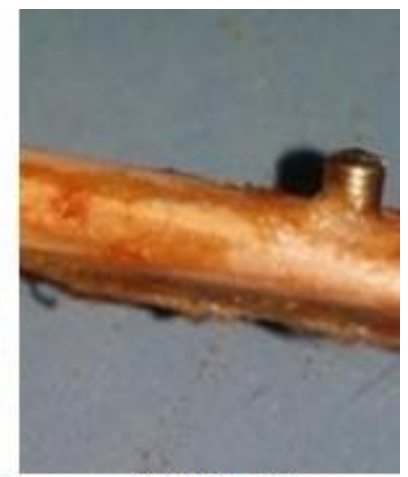

(B) left tibia
Figure 3: Surgical site after 6weeks

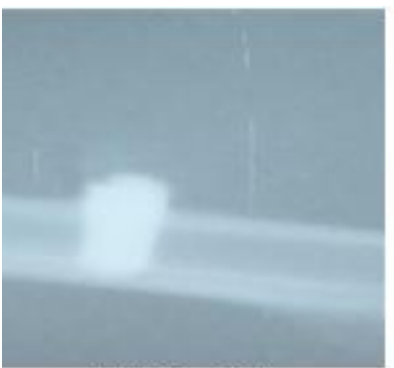

(A)Right tibia

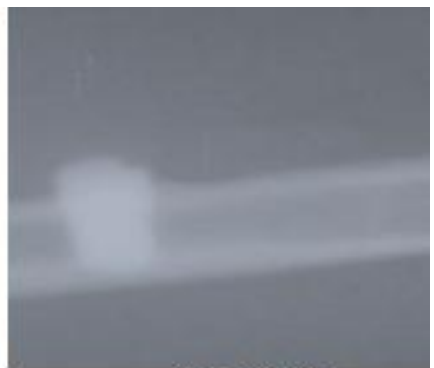

(B) Left tibia
Figure 4: $\mathrm{X}$ - ray radiograph after 6weeks

\section{Histological Testing}

From both 2 nd and 6th weeks healing periods three rabbit anesthetized by overdose anesthetic solution and then scarified for histological examination by optical microscope

\subsection{Histological features of implant after 2 and 6 weeks healing periods}

\section{1) Two weeks after implantation}

\section{a) Nano HA coated cp Ti implants}

Histological view of nano HA coated screw implanted in rabbit tibia after 2 weeks illustrates border area filled with fibrous connective tissue, fibroblasts, new blood vessels and osteoprogenitor cells(figure 5) indicating delay in bone formation 

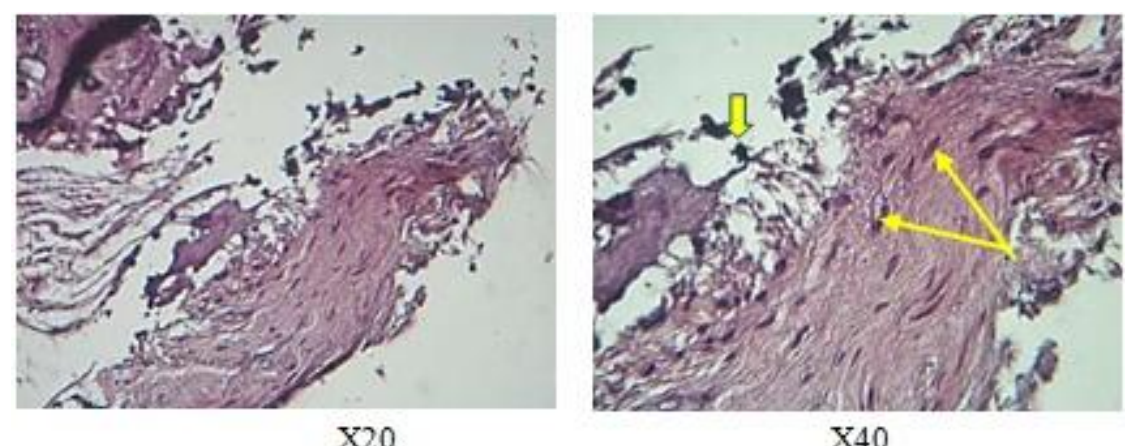

Figure 5: Histological view shows fibrous connective tissue. Fibroblasts (Arrows), and osteoprogenitor cells (arrow head) H\&E stain X20\&X40

b) Nano HA, Chitosan and Collagen mixture coated cp Ti

Histological view of nanoHA, chitosan and collagen mixture coatedscrews after two weeks of implantation, shows thread area filled with newbone trabeculae which filled with large

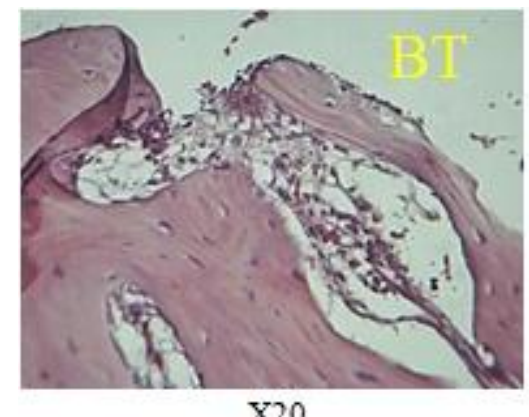

$\mathrm{X} 20$ size osteocytes surrounded by osteoblastand osteoclast cells. (Figure 6). Indicating active bone formation

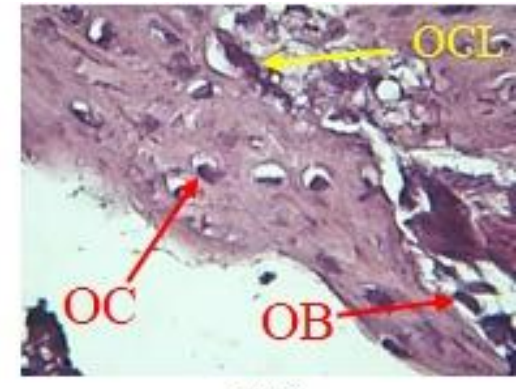

$\mathrm{X} 40$

(Figure 6):Histological View Shows New Bone Trabeculae Filled With Osteocytes (OC) Andsurrounded by osteoblasts (OB) and osteoclasts (OCL), H\&E stainX20\& X40

\section{2) Six weeks after implantation:}

\section{a) Nano HA coated cp Ti}

The histological view of nanoHA coated cp Ti screws implanted in therabbit tibia after six weeks shows the thread site with filled new bone, which filled with osteocytecells and osteoblast lining the harversian canal (figure7).

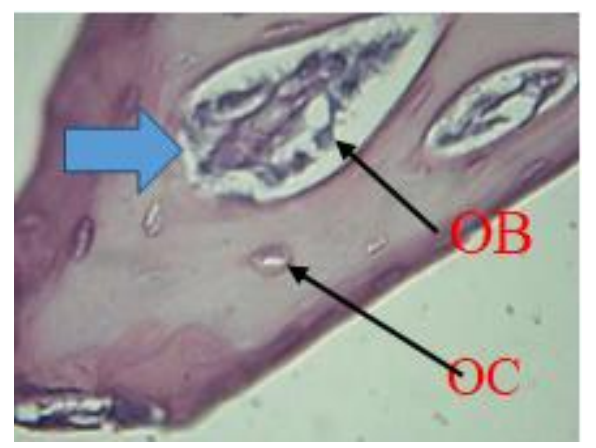

Figure 7: Histological view shows new bone filled with osteocytes (OC) and Harversian canal (Blue arrow) lined by osteoblasts (OB), H\&E stain X40

\section{b) Nano HA, Chitosan and Collagen coated cp Ti}

The histological view of nanoHA, chitosan\&collagen mixture coated cp Ti screws after six weeks of implantation shows formation of mature bone at the thread area. The mature bone filled with lamellar arrangement of osteocytes and lined by osteoblasts (figure 8). With indication of acceleration in bone formation.

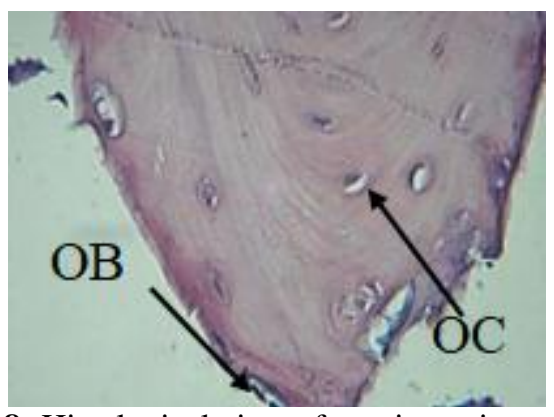

Figure 8: Histological view of previous picture shows mature bone filled with lamellararrangement of osteocytes

(OC) and lined by osteoblasts (OB) reversal line (blackarrow), H\&E stain X40.

\section{Discussion}

Due to Excellent biocompatibility and lack of toxicity of commercially pure (cpTi) titanium so it is the material most often used in implant manufacturing. Many investigations are being used in an effort to gain desired outcomes at the bone-implant interface ${ }^{(13)}$. Many studies have focused on surface properties and chemical composition as a way to control bone healing around dental implants ${ }^{(14)}$.The advantage of dip coating was ability of producing multiple thin coatings about $1000 \mathrm{~nm}$ thick with a high degree of 


\section{International Journal of Science and Research (IJSR) \\ ISSN (Online): 2319-7064}

Index Copernicus Value (2015): 78.96 | Impact Factor (2015): 6.391

uniformityif suitable additives are chosen as $\mathrm{P} 2 \mathrm{O} 5(\mathrm{P} 2 \mathrm{O} 5$ added to the suspension as a thickening material)and reduction in sintering temperature is also possible ${ }^{(15)}$.

The radiographic examination in this study, showed a direct contact between bone and implant, without radiolucent zones or anyabnormal reaction to the implant. However, the absence of such zones is not mean osseointegration, since it is difficult for a clinician to detect changes in the radiographicbone loss at $0.1 \mathrm{~mm}$ resolution, Histological analysis is the most reliable method to assess stability of implants, and can be performed at any time of implantation

During progressing of the implantation time, a part of the bone appeared on the surface of the implant.This indicated that the improvment in contactbetween the implant and bone with time resultingin better mechanical properties of bone implantinterface. This agreed with Jayaramon et al , ${ }^{(17) .}$

The results of present study showed that placing of coated implants within living bone resulted in osseointegrated implants under typical biological environment for bone formation, the rigidity of connection between osseointegrated implant and the bone and maturation of bone increases with time. This result agrees with Liu et al. 7 Waheed $2013^{(18 \& 19)}$.

Regardless of the type of coating material and the duration of the implantation the results gained revealed that no inflammatory reaction had happened during the experimental periods. This is in agreement with the results of Mano et al., 2002 and Lins et al., 2003

\section{Conclusion}

In this study coating with nano HA, chitosan and collagen composite coating on dental implants showed better results than nano HA coating implants. It shows rapid bone formation and maturation at both period of healing.

\section{References}

[1] The glossary of prosthodontic terms-, J Prosth Dent. 94(1), 58 (July 2005).

[2] Ulrich Joos, Andre Büchter, Hans-Peter Wiesmann, Ulrich Meyer, -Strain driven fast osseointegration of implants-, Head \& Face Medicine, 1, 6 (2005).

[3] John M. Powers, Ronald L. Sakaguchi, Dental Implants- in Craig's Restorative Dental Materials: Dental Implants, 12th Editon, Elsevier, 555-569 (2006).

[4] Eisenbarth, E.; Velten, D.; Müller, M.; Thull, R. \& Breme, J. (2004). Biocompatibility of beta- stabilizing elements of titanium alloys. Biomaterials, Vol.25, No.26, pp. 5705-5713, ISSN 0142-9612.

[5] Hallab, N.J.; Skipor, A. \& Jacobs, J.J. (2003). Interfacial kinetics of titanium- and cobalt-based implant alloys in human serum: metal release and biofilm formation. Journal of Biomedical Materials Research Part A, Vol.65, No.3, pp. 311-318, ISSN 1549-3296.

[6] Mendonça, G.; Mendonça, D.B.; Aragão, F.J. \& Cooper, L.F. (2008). Advancing dental implant surface technology--from micron- to nanotopography. Biomaterials Vol.29, No.28, pp. 3822-3835, ISSN 0142-9612.

[7] Hench, L.L. \& Wilson, J. (1984). Surface-active biomaterials. Science, Vol.226, No.4675, pp. 630-636, ISSN 0036-8075.

[8] Hayakawa T, Yoshinari M, Nemoto K, Wolke JGC, Jansen JA. (2000). Effect of surface roughness and calcium phosphate coating on the implant/bone response. Clinical Oral Implant Research. Vol. (11): 296-304, ISSN 0905-7161.

[9] Motz W, Bentley C, Tasto J. Bio absorbable implants in orthopedics: New developments and clinical circone applications. J Am Acad Orthop Surg 2001;9:280-8.

[10] Mizuno M, Fujisawa R and Kuboki Y 2000 Type I collagen-induced osteoblastic differentiation of bonemarrow cells mediated by collagen-alpha2beta1 integrin interaction J. Cell. Physiol. 184 207-13

[11]Di Martino A, Sittinger M, Risbud MV.Chitosan: A ersatile biopolymer for orthopedic tissue-engineering. Biomaterials2005;26:5983-90.

[12]Hussien MN. Evaluation of pure dental titanium implants coated with mixture of nano titanium oxide and nano hydroxyapatite, AMaster thesis, Collage of dentistry, University of Baghdad, 2015.

[13] Stanford CM Surface Modification of Biomedical and Dental Implants and the Processes of Inflammation, Wound Healing and Bone Formation. Int $\mathbf{J}$ Mol Sci 2010; 11(1): 354-69.

[14] Mendonça G, Mendonça DBS, Simoes LGP, Andre' L, Arau' jo AL, Leite ER, Duarte WR, Araga o FJL, Cooper LF. The effects of implant surface nanoscale eatures on osteoblastspecific gene expression. Biomaterials 2009;30,4053-62.

[15] Aksakal B, Hanyaloglu C. Bioceramic dip-coating on Ti-6Al-4V and 316L-SS implant materials. J Materials Science 2008;19(5): 2097-104.

[16] Astumi M, Park SH, Wang HL. Methods used to asses implant stability. Int J Oral Maxillofac Imp 2007; 22. 743-754.

[17] Jayaramon M, Meyer U, Bnehner M, Joos U, Wiesmann H. Influence of Titanium Surfaces on Attachement of Osteoblasts-Like Cells, In Vitro. Biomaterials 2004; 25(4): 625-31.

[18] Liu X, Chu PK, Ding C. Surface modification of titanium, titanium alloys, and related materials for biomedical applications. Materials Science and Engineering J, 2004; 47(3 - 4): 49 - 121.

[19] Waheed AS .Mechanical and histological evaluation of nanozirconium oxide coating on titanium alloy ( $\mathrm{Ti}-$ 6Al-7Nb) dental implants .Master thesis, Collage of Dentistry, University of Baghdad, 2013.

[20] Mano T, Ueyama Y, Ishikawa K, Matsumura T, Suzuki $\mathrm{K}$. Initial tissue response to a titanium implant coated with apatite at room temperature using a blast coating method. Biomaterials .2002; 23:1931-36.

[21]Lins L, Santana E, Falcao A, Martin P, Calmon T, Sarmento V. The influence of hydroxyapatite on bone healing in titanium implants as shown by scanning electron microscopy. Braz J morphol Sci. 2003; 20(1):25-29.

\section{Volume 6 Issue 7, July 2017 www.ijsr.net}

